\title{
Ultrasound Guided PECS II Block versus Thoracic Epidural in Modified Radical Mastectomy for Post-Operative Pain Relief
}

\author{
HORIA A. FARRAN, M.D. and SAWSAN G. MOHAMED, M.D.
}

The Department of Anaesthesiology, Intensive Care and Pain Management, Faculty of Medicine for Girls Al-Azhar University

\begin{abstract}
Background: Breast cancer is women's most common malignancy and has steadily increased incidence over the past decade. Despite recent breast cancer surgery advances, this procedure is often associated with postoperative pain, nausea, and vomiting, contributing not only to increased patient discomfort, but also to extended hospital stays and associated costs. A significant risk factor for the development of chronic pain following breast surgery is acute postoperative pain due to insufficient or ineffective pain control.
\end{abstract}

Aim of Study: Assess the effectiveness of ultrasound guided PECS block to thoracic epidural blockage in breast cancer surgery to minimize postoperative pain, analgesic requirements and complications.

Patients and Methods: After Ethical Committee at AlZahraa University Hospital accepted, 50 female patients, age from 42-67 years, were included in the study with ASA physical status I-II patients scheduled for unilateral modified radical mastectomy and axillary lymph node dissection, randomly blind assigned, split two different groups of 25 patients in each, Thoracic epidural block (TEB group); patients were received a single shot of $15 \mathrm{ml}$ of $0.25 \%$ bupivacaine between T4 and T5 vertebrae. PECS group: Ultrasound-guided PECS block, the patients were received $0.25 \%$ of $10 \mathrm{ml}$ bupivacaine injected at fiscal plain between the pectoral $\mathrm{s}$ major and minor muscles (PECS I) also $0.25 \%$ of $20 \mathrm{ml}$ of pectoralminor injection above the Serratus anterior muscle (PECS II). Primary outcome in the form of post-operative visual analogue scale (VAS) to assess pain in density. Secondary outcome in the form heart rate (HR), mean blood pressure (MBP) intra operative fentanyl consumption and, first request of analgesia, total amount of pethidine $/ 24 \mathrm{hrs}$. were recorded and other any post-operative complication were assessed.

Results: The patients of TEB group, the mean heart rate and the mean MAP were highly significant decrease than PECS group. Intra operative fentanyl consumption as statistically significant decrease in PECS group compared with TEB group. VAS pain scores was high statistically significant decrease immediately and at $4 \mathrm{hrs}$. post-operative in PECS group than TEB group. The time for the first request for pethidine was highly significantly longer in the PECS group than in TEB group. Amount of pethidine at $24 \mathrm{hrs}$. was high significant lower in PECS group in comparison with TEB

Correspondence to: Dr. Horia A. Farran, The Department of Anaesthesiology, Intensive Care and Pain Management, Faculty of Medicine for Girls Al-Azhar University group. Complications recorded as hypotension and bradycardia post-operative nausea and vomiting (PONV) occurrence in TEB group.

Conclusion: PECS blocks provided superior post-operative analgesia, low pain scores and less total pethidine consumption in the early postoperative period and maintained hemodynamic stability compared to TEB.

Key Words: TEB group - Post-operative nausea - Voming $P O N V-P E C S$.

\section{Introduction}

BREAST surgery is one of the most common types of hospital surgery. Much postoperative pain can be associated with even relatively minor breast surgery and can be associated with significant postoperative pain [1]

Several regional anesthetic techniques are used as a thoracic epidural block (TEB), thoracic paravertebral block (TPVB). TEB is the gold standard technique following breast surgery, but there is still a problem with the adequacy of thoracic and axillary blockage during lymph node dissection [2]. On the other hand, attributed to the recent application of used ultrasound (US) in anesthetic practice by anesthesiologists has become increasingly popular for needle guidance in local and regional anesthetic techniques [3]. Type I PECS block is a simple approach, easy and reliable superficial block that targets lateral and medial pectoral nerves on an interfacial plane between minor muscles (PMM) and pectoral major (PMM) [1] Second version of the PECS block type I called "modified PECS's block" or PECS block type II. This approach aimed to block the axilla that is vital for axillary clearances and the intercostal nerves, necessary for wide excisions [4] which can provide analgesia after breast surgery.

Aim of the work:

To assess the effectiveness of thoracic epidural blockage versus ultrasonic guided PECS block 
during modified radical mastectomy for postoperative pain relief.

\section{Patients and Methods}

A randomized, double-study was carried at AlZahraa University Hospital from March 2016 to March 2017, after Ethical Committee Approval, informed consent was taken from patients, this prospective on 50 adult patients with their ages, ranging from 42-67 years old of American Society of Anesthesiologists classification (ASA) grade I or II scheduled for unilateral total mastectomy and axillary lymph node dissection through under general anathesia were enrolled in this study with Exclusion criteria: Patients were excluded if lack of patient consent. History of sensitivity to local anesthetic. Bleeding disorders or receiving anticoagulant, body mass index $(\mathrm{BMI})>35 / \mathrm{kg} / \mathrm{m} 2$. Spine or chest wall deformity, infection at the thoracic injection site, chronic analgesic use, chronic pain syndrome and psychiatric disease.

Routine preoperative assessment was done to all patients including history, clinical examination, laboratory investigations (complete blood picture $\mathrm{CBC}$, kidney and liver function tests, prothrombin time, partial thromboplastin time, INR, serum glucose level and serum electrolytes. During preoperative visit and enrollment to the study, patients were instructed about Visual Analogue Scale (VAS) for pain assessment by an anesthesiologist involved in the study. VAS is a horizontal line, $10 \mathrm{~cm}$ in length, ranging from 0 (no pain) to 10 (worst pain). The patients mark on the line the point they feel corresponds to their pain.

Randomization was achieved by sealed envelope method, used by an anesthesiologist who did not participate in the study pulled out an envelope for each patient and prepared the study and patients were allocated randomly into two equal groups (25 patient in each group).

Thoracic epidural block (TEB) group; patients were received a single shot of $15 \mathrm{ml}$ of $0.25 \%$ bupivacaine between $\mathrm{T} 4$ and $\mathrm{T} 5$ vertebrae.

PECS group: Ultrasound-guided PECS block, the patients were received $0.25 \%$ of $10 \mathrm{ml}$ bupivacaine injected at fascil plain between the pectoral $\mathrm{s}$ major and mino muscles (PECS I) also $0.25 \%$ of $20 \mathrm{ml}$ of pectoral-minor injection above the Serratus anterior muscle (PECS II).

Assessment parameters; The hemodynamics: Heart rate (HR) and mean arterial blood pressure (MAP) were tracked for pre-operative (basal), $15 \mathrm{~min}, 30 \mathrm{~min}$ and every $15 \mathrm{mins}$ from the beginning of surgery, then immediate post-operative and 6 , 12,18 , and 24 hours. Intraoperative fentanyl consumption and post-operative VAS to assess pain intensity, first analgesic requested and maximum opioid analgesic consumption for 24 hours.

Also Complications must be recorded; Postoperative nausea and vomiting (PONV) and was treated by $8 \mathrm{mg}$ of ondansetron, hypotension; it was defined as a reduction of more than $20 \%$ of the baseline MAP and treated with increments of $6 \mathrm{mg}$ bolus ephedrine IV and $250 \mathrm{ml}$ lactated ringer solution, bradycardia; defiant as a pulse rate of $<50 \mathrm{beat} / \mathrm{min}$ and IV atropine $(0.01 \mathrm{mg} / \mathrm{kg})$ treatment.

ON arrival to operating theater $18 \mathrm{G}$ peripheral intravenous cannula was inserted at the contralateral upper limb to the side of surgery, Ringer's solution was infused $(8 \mathrm{ml} / \mathrm{kg})$ to replenish the overnight fasting hours, all patients premeditated with (0.01$0.1 \mathrm{mg} / \mathrm{kg})$ midazolam and $(0.5-1 \mathrm{ug} / \mathrm{kg})$ fentanyl. In the operating room every patient was attached to a standard monitor as electrocardiography, pulse oximetry and non-invasive blood pressure (Drager Infinity monitor). All patients were receiving their regional block according to the technique of each group before induction of general anesthesia.

In the TEB group, patients were placed sitting upright with the neck and back flexed and the shoulders relaxed forward. The T4-5 intervertebral space in the middle line was identified. Then the area of the back was disinfected and Skin wheal of lidocaine local anesthetic $2 \%$ of site of insertion was done. Then Tuohy 18 G needle (Protex, Regional Anesthesia Tray, Smith Medical International Ltd, UK) was inserted $1-2 \mathrm{~cm}$ lateral to the spinous process of the vertebra through paramedian approach. Once the epidural space identified $15 \mathrm{ml}$ of $0.25 \%$ bupivacaine was injected.

In the PECS group patients were placed in supine position. The block was performed on the side of surgery with the ipsilateral upper limb in abduction position. After the skin of the infraclavicular region disinfected and preparing the US probe (high frequency $6-13 \mathrm{MHz}$ linear array) and adjusting the depth of 4 to $6 \mathrm{~cm}$ and gain of US machine Ultrasound machine (Sonosite, M-turbo, Sonosite Inc, USA) a linear probe of high frequency (6-13MHz). The 20-gauge echogenic needle introduced in-plane approach from medial to lateral and $10 \mathrm{ml}$ of bupivacaine $0.25 \%$ was injected into the fascial plane between pectoralis muscles in order to block medial and lateral pectoral nerve (PECS I). Then the needle was reinserted into the fascial plane between pectoralis minor and serratus 
anterior muscle and $20 \mathrm{ml}$ of bupivacaine $0.25 \%$ was injected in increments of $5 \mathrm{ml}$ after negative aspiration in order to block intercostals II-III-IV$\mathrm{V}-\mathrm{VI}$ and the long thoracic nerve (PECS II).

General anesthesia was induced in all patients with fentanyl (1-2ug/kg), propofol $(1-2 \mathrm{mg} / \mathrm{kg})$ and an intuitive dose of cisatracurium $(0.15 \mathrm{mg} / \mathrm{kg})$, endotracheal intubation secured the airway.

Anesthesia was maintained with isoflurane (1$2 \%$ ) and an incremental dose of cisatracurium $0.03 \mathrm{mg} / \mathrm{kg}$ and $\mathrm{O}_{2} /$ air mixture with a fraction of $60 \%$ inspired $\mathrm{O}_{2}$. Controlled ventilation was accomplished by a ventilator (Drager, fabius plus made in USA) with a tidal volume of $6-8 \mathrm{~mL} / \mathrm{kg}$ and an $\mathrm{I} / \mathrm{E}$ ratio of $1: 2$ to maintain a tidal carbon dioxide voltage of approximately $35-40 \mathrm{mmHg}$.

Heart rate (HR) and mean arterial blood pressure (MAP) were maintained by additional bolus doses of 25 fentanyl within $20 \%$ of the baseline value.Hypotension was characterized as a decrease of more than 20 percent of the MAP base line and treated with increments of ephedrine iv $6 \mathrm{mg}$ bolus doses and $250 \mathrm{ml}$ lactated ringer solution.

All patients were reversed with neostigmine $0.04 \mathrm{mg} / \mathrm{kg}$ and atropine $(0.01-0.02) \mathrm{mg} / \mathrm{kg}$, neuromuscular obstruction were antagonized at the end of surgery.

Patients are transferred to the post-anesthetic care unit (PACU) following recovery from anesthesia.

All patients received IV paracetamol 1 gm (injectemol, Pharco B International, Pharma-Tech) and Ibuprofen (oral) 400mg and meperidine (pethidine) rescue analgesia $30 \mathrm{mg} / \mathrm{IV}$ for patients with VAS $>4$.

\section{Statistical analysis:}

Sigma plot 12 was used for sample size calculation, where a sample size of 25 patients per group will achieve $83 \%$ power to detect a difference of $50 \%$ in proportion of postoperative complications. Data were collected, revised, coded and entered to the Statistical Package for Social Science (IBM SPSS) version 23 . The quantitative data were presented as mean, standard deviations and ranges. The comparison between two groups regarding quantitative data with parametric distribution was done by using Independent $t$-test while with nonparametric distribution was done by using MannWhitney test. Also the comparison between the two groups regarding qualitative data was done by using Chi-square test. The confidence interval was set to $95 \%$ and the margin of error accepted was set to $5 \%$. So, the $p$-value was considered significant at the $p<0.05$.

\section{Results}

As regards to demographic data: There were no significant differences between the two studied groups in terms of age, weight, BMI, Height and ASA physical status classification $(p>0.05)$. As shown in Table (1).

Table (1): Comparison between TEB and PECS regarding age, weight, height, BMI, surgical duration and ASA.

\begin{tabular}{|c|c|c|c|c|}
\hline & \multicolumn{2}{|c|}{ Groups } & \multirow[b]{2}{*}{$\begin{array}{c}\text { Independent } \\
t \text {-test }\end{array}$} & \multirow[b]{2}{*}{$\begin{array}{c}p- \\
\text { value }\end{array}$} \\
\hline & $\begin{array}{c}\text { TEB } \\
(\text { No. }=25)\end{array}$ & $\begin{array}{c}\text { PECS } \\
(\text { No. }=25)\end{array}$ & & \\
\hline $\begin{array}{l}\text { Age (years): } \\
\quad \text { Mean } \pm \text { SD }\end{array}$ & $54.38 \pm 5.93$ & $56.41 \pm 6.54$ & 1.195 & $0.237 \mathrm{~ns}$ \\
\hline $\begin{array}{l}\text { Weight }(K g): \\
\quad \text { Mean } \pm \text { SD }\end{array}$ & $74.23 \pm 9.23$ & $76.34 \pm 8.38$ & 0.846 & $0.401 \mathrm{~ns}$ \\
\hline $\begin{array}{l}\text { Height }(\mathrm{cm}): \\
\quad \text { Mean } \pm \text { SD }\end{array}$ & $166.12 \pm 6.89$ & $168.45 \pm 7.54$ & 1.141 & $0.259 \mathrm{~ns}$ \\
\hline $\begin{array}{r}B M I\left(\mathrm{~kg} / \mathrm{m}^{2}\right): \\
\quad \text { Mean } \pm \mathrm{SD}\end{array}$ & $28.56 \pm 1.65$ & $27.67 \pm 1.89$ & 1.774 & 0.082 \\
\hline $\begin{array}{l}\text { Surgical durati } \\
\text { (min): } \\
\quad \text { Mean } \pm \text { SD }\end{array}$ & $92.43 \pm 11.56$ & $93.74 \pm 12.45$ & 0.385 & $0.705 \mathrm{~ns}$ \\
\hline ASA: & $\mathrm{N} \%$ & $\%$ & $\begin{array}{c}\text { Chi square } \\
\text { test }\end{array}$ & $p$-value \\
\hline $\begin{array}{l}\text { I } \\
\text { II }\end{array}$ & $\begin{array}{ll}11 & 44.0 \\
14 & 56.0\end{array}$ & $\begin{array}{ll}13 & 52.0 \\
12 & 48.0\end{array}$ & 0.321 & $0.571 \mathrm{~ns}$ \\
\hline
\end{tabular}

NS $=$ Non-significant at $p$-value $>0.05$.

As regards to heart rate; it revealed no statistically significant difference between TEB and PECS regarding basal time $\mathrm{HR}$ at $24 \mathrm{hrs}$. post-operative HR. While a highly statistically significant decrease in TEB than PECS at the mean hrs. recorded 15, 30, 45, 60, 90, 120min, 6 hrs., 12 hrs., 18 hrs. after the injection are shown in Fig. (1) ( $p$-value <0.01).

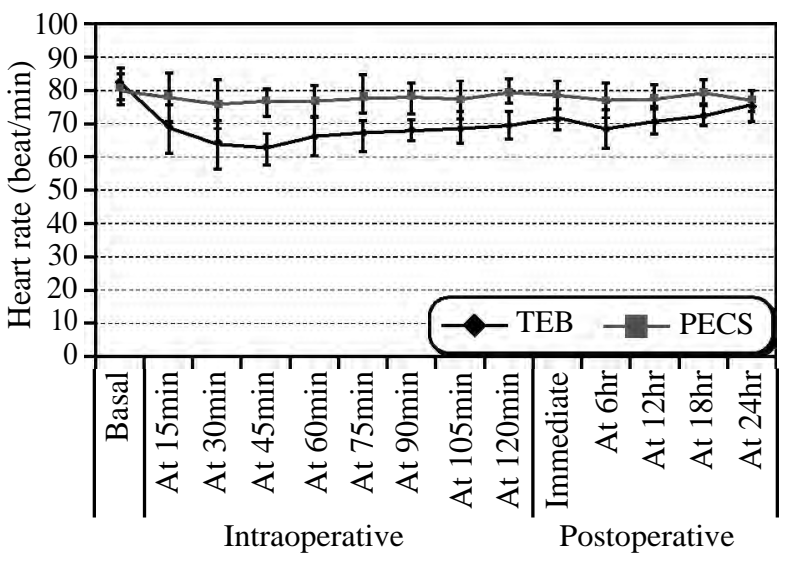

Fig. (1): Shows comparison between TEB and PECS regarding HR changes (beat/min). 
As regards to mean arterial pressure; it revealed no statistically significant difference between TEB and PECS regarding basal time MAP, and at $24 \mathrm{hr}$ postoperative. While a highly statistically significant difference between TEB and PECS regarding Intraoperative time and postoperative time MAP $(p \leq 0.001)$. Fig. (2).

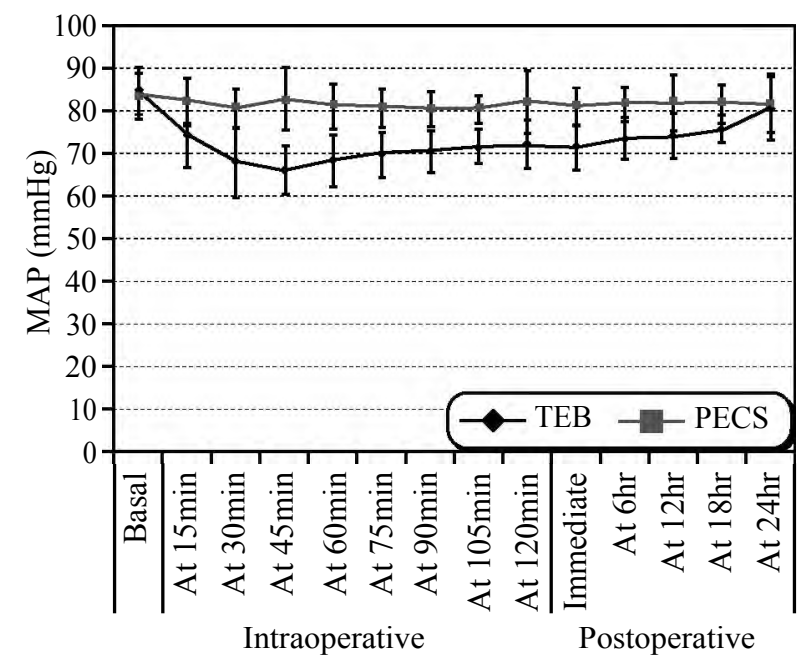

Fig. (2): Shows comparison between TEB and PECS regarding MAP ( $\mathrm{mmHg})$ changes.

As regards to Intra operative fentanyl consumption; It revealed statistically significant difference between TEB and PECS regarding Intra operative fentanyl consumption was significantly lower in PECS group $(115.18 \pm 12.69)$ compared with TEB group $(124.34 \pm 15.45)(p \leq 0.05)$. As shown in (Table 2).

Table (2): Comparison between TEB and PECS regarding intra operative fentanyl consumption (ug).

\begin{tabular}{|c|c|c|c|c|}
\hline & \multicolumn{2}{|c|}{ Groups } & \multirow{2}{*}{$\begin{array}{c}\text { Independent } \\
t \text {-test }\end{array}$} & \multirow{2}{*}{$\begin{array}{c}p- \\
\text { value }\end{array}$} \\
\hline & $\begin{array}{c}\text { TEB } \\
(\text { No. }=25)\end{array}$ & $\begin{array}{c}\text { PECS } \\
(\text { No. }=25)\end{array}$ & & \\
\hline $\begin{array}{l}\text { Intra oper } \\
\text { fentanyl } \\
\text { amount/ug }\end{array}$ & $124.34 \pm 15.45$ & $115.18 \pm 12.69$ & 2.291 & $0.026 \mathrm{~S}$ \\
\hline
\end{tabular}

$\mathrm{S}=$ Significant at $p$-value $\leq 0.05$.

As regards to VAS pain scores throughout the first $24 \mathrm{hr}$. post-operative showed that there was highly statistically significant decrease immediate and at $4 \mathrm{hr}$., at $12 \mathrm{hr}$. post-operative in PECS group $(p$-value $<0.01)$. VAS scores $\geq 4$ was treated with rescue analgesic while no statistically significant difference between TEB and PECS at 6 hr., $18 \mathrm{hr}$., $24 \mathrm{hr}$., regarding at VAS pain $(p>0.05)$. As shown in Fig. (3).

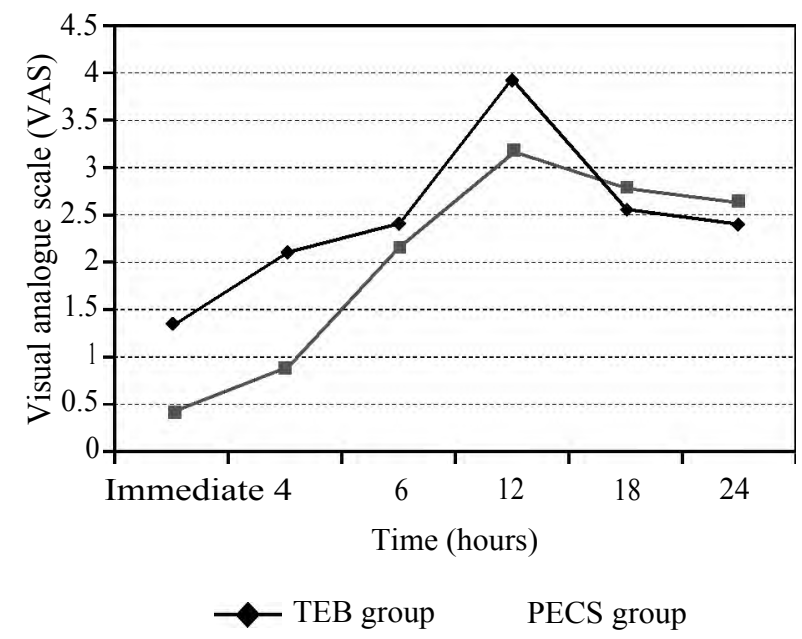

Fig. (3): Shows comparison between TEB and PECS regarding VAS.

As regards to the first request for analgesia and Amount of pethidine (mg) needed /24; The time for the first request for pethidine was high significantly longer in the PECS group [(481.33 \pm 75.36$)$ min.] than in the TEB group $[(232.67 \pm 83.12) \mathrm{min}$. $]$. Amount of pethidine at $24 \mathrm{hrs}$. was high significant lower in PECS group [(43.67 \pm 14.77$) \mathrm{mg}]$ in comparison with TEB group [(62-43 \pm 11.34$) \mathrm{mg}] \mathrm{PV}$ $\leq 0.001 /$ HS. As shown in Table (3).

Table (3): Comparison between TEB and PECS regarding time to the first request for analgesia and amount of pethidine/24hs.

\begin{tabular}{|c|c|c|c|c|}
\hline & \multicolumn{2}{|c|}{ Groups } & \multirow{2}{*}{$\begin{array}{c}\text { Independent } \\
t \text {-test }\end{array}$} & \multirow{2}{*}{$\begin{array}{c}p- \\
\text { value }\end{array}$} \\
\hline & $\begin{array}{c}\text { TEB } \\
(\text { No. }=25)\end{array}$ & $\begin{array}{c}\text { PECS } \\
(\text { No. }=25)\end{array}$ & & \\
\hline $\begin{array}{l}\text { Time to first } \\
\text { need } \\
\text { analgesia } \\
\text { (min) }\end{array}$ & $232.67 \pm 83.12$ & $481.33 \pm 75.36$ & 11.08 & $\leq 0.001 \mathrm{HS}$ \\
\hline $\begin{array}{l}\text { Amount of } \\
\text { pethidine } \\
/ 24 \mathrm{hr} .\end{array}$ & $62.43 \pm 11.34$ & $43.67 \pm 14.77$ & 5.037 & $\leq 0.001 \mathrm{HS}$ \\
\hline
\end{tabular}

HS $=$ Significant at $p$-value $\leq 0.001$.

Significant bradycardia with decrease heart rate $<50 \mathrm{~b} / \mathrm{min}$. occurred in 7 patients $(28.0 \%)$ in TEB group, and was managed by atropine I.V $(0.01 \mathrm{mg} /$ $\mathrm{kg})$. Hypotension was significantly higher in TEB groups occur in 10 patients as compared to PECS. PONV was seen in 5 patients in TEB group $(20.0 \%)$ and 3 patients in PECS group $12.0 \%$, and was treated with $8 \mathrm{mg}$ ondansetron. As shown in Table (4). No other complications were recorded as such as pneumothorax, vascular puncture, or local anesthetic toxicity in the two studied groups. 
Table (4): Comparison between TEB and PECS regarding side effects.

\begin{tabular}{|c|c|c|c|c|c|c|}
\hline \multirow{3}{*}{$\begin{array}{l}\text { Complications } \\
\text { recorded }\end{array}$} & \multicolumn{4}{|c|}{ Groups } & \multirow{3}{*}{$\begin{array}{c}\text { Chi square } \\
\text { test }\end{array}$} & \multirow{3}{*}{$\begin{array}{c}p- \\
\text { value }\end{array}$} \\
\hline & \multicolumn{2}{|c|}{$\begin{array}{c}\text { TEB } \\
(\text { No. }=25)\end{array}$} & \multicolumn{2}{|c|}{$\begin{array}{c}\text { PECS } \\
(\text { No. }=25)\end{array}$} & & \\
\hline & $\mathrm{N}$ & $\%$ & $\mathrm{~N}$ & $\%$ & & \\
\hline Hypotension & 10 & 40 & 3 & 12.0 & 5.094 & $0.024 \mathrm{~S}$ \\
\hline Bradycadia & 7 & 28.0 & 1 & 4.0 & 5.357 & $0.021 \mathrm{~S}$ \\
\hline PONV & 5 & 20.0 & 3 & 12.0 & 0.59 & $0.440 \mathrm{~ns}$ \\
\hline
\end{tabular}

NS $=$ Non-significant at $p$-value $>0.05$

$\mathbf{S}=$ Significant at $p$-value $\leq 0.05$.

\section{Discussion}

The present study was conducted to compare the efficacy and safety of the PECS II block with TEB for postoperative analgesia, hemodynamics and complications in patients with unilateral segmental or full mastectomy and axillary dissection of the lymph node.

As regards to hemodynamic measures (HR and MAP), the findings of the current study revealed that there was no statistically significant difference in baseline values ( $p$-value $>0.05$ ) between the two groups examined, while there was a highly statistically significant decrease in the TEB group of $30,45,60,90,120 \mathrm{~min}, 6 \mathrm{hr}, 12 \mathrm{hr}$ and $18 \mathrm{hr}$ compared to PECS ( $p$-value $<0.01$ ). While PECS group reported no significant hemodynamic difference $(p$-value $>0.05)$.

This hemodynamic response is a duo to the TEB group's bilateral sympathetic blockade. Since the PECS blocks are peripheral blocks of the nerves, they do not result in hemodynamic sympathtectomy.

In line of present study Khalil et al., [5] they found that MAP in the thoracic epidural group was significantly reduced relative to both the baseline values in the same group and the Serratus Anterior Plane Block group compared to Thoracotomy Pain

In agreement with studied done by Bashandy and Abbas [6], they performed a randomized study of 120 patients receiving either GA plus PECS block or GA alone, and studied of Blancoa et al. [4] performed a PECS II block in 50 patients undergoing modified radical mastectomy. They reported there were no change in PECS block hemodynamics because there is no sympathetic block associated with it.

The current study show significantly lower intraoperative fentanyl was used in the PECS group compared to TEB. Furthermore, the total amount of analgesic (pithidine) requirement in the PECS group was decreased during the first 24 hours after surgery without significant difference between the two groups studied.

In the same line with this results study of Bashandy and Abbas [6] who studied PECS block vs. GA in breast cancer surgery using $0.25 \%$ bupivacaine, they found that the mean intraoperative fentanyl intake in the PECS group was significantly lower than in the GA group.

The results were matched with ELdeen [7] who found a significant prolongation of the time of postoperative analgesia with a significant decrease of the fentanyl requirement when they compared PECS II block with thoracic spinal in breast cancer surgery using $20 \mathrm{ml}$ of levobupivacaine $0.5 \%$.

In agreement with the present study, Razek et al., [8] who conducted a study about ultrasound guided pectoral nerve blocks versus serratus intercostal plane block in breast surgeries, showed that intra operative fentanyl consumption was significantly lower in PECS group, also, the total amount of postoperative morphine was significantly lower in the PECS group than in the GA group.

In other hand Morioka et al., [9] who studied (PECS with TIVA + remifentanile infusion) with GA (TIVA + remifentanile infusion) for breast cancer surgery found no difference between the two groups in fentanyl consumption, but the mean intraoperative demand for remifentanil in the PECS community was significantly lower.

In the present study, pain scores measured by VAS and the results showed that patients with PECS block reported less intense pain in the immediate post-operative at $4 \mathrm{hr}$ and $12 \mathrm{hr}$ postoperative than TEB and PECS community with highly statistically significant reduction in VAS at $12 \mathrm{hrs}$. The two groups reported an insignificant difference in VAS at $24 \mathrm{hr}$.

Supporting to present results, study by ELdeen, [7] found that, relative to the thoracic spinal cord in breast surgery, VAS was significantly reduced in the PECS unit during surgery and the first $24 \mathrm{~h}$ postoperative. Also Razek et al., [8] and Torre et al., [10] stated that VAS was significant lower in the PECS group than TEB.

With respect to hypotension and bradycardia, the results of the current study showed a significant decrease in the incidence of hypotension and bradycardia in the PECS group compared to TEB. This might have been derived from the absence of sympathetic block with PECS block. 
Our finding is in consistent with the studies of, Soni et al., [11] who performed a double-blind, randomized study of 60 women scheduled for unilateral breast surgery to determine hypotension incidence and vasopressor need, in the epidural group of patients, perturbations are more correlated with the need for more fluid \& vasopressor.

In terms of PONV, this study showed the incidence of PONV in the PECS group is lower compared to the TEB group.

In agreement with the results of the current study, Bashandy and Abbas, [6] and Yuki et al., [12] they studied MRM patients with and without PECS blocks under GA, found that the PECS group had lower PONV scores in MRM surgery.

In contrast $\mathrm{Li}$ et al., [13] found no significant different between PECS and TEP in the incidence of post-operative nausea and vomiting in MRM patients.

\section{Conclusion:}

The PECS block is effective and safe technique which provides better pain relief compared with the TEB and reduced post-operative opioid consumption. Therefore, the PECS block can be used safely for post-operative analgesia in patient undergoing breast surgery to avoid risk develop chronic post-mastectomy pain which reduces quality of life.

\section{References}

1- BLANCO R.: The PECS block': A novel technique for providing analgesia after breast surgery. Trunk blocks for abdominal surgery; Anesthesia, Vol. 65: Issues1, 2010.

2- PEREIRA C. and CARMO V.: Evaluation of Three Anesthesic Techniques in Breast Surgery. Journal of the Senologic International Society. Oct. 10; 1 (3), 2012.

3- GUPTA P.K. and HOPKINS P.M.: Ultrasound guided peripheral and regional nerve block In Practical ultrasound in anesthesia for critical care and pain management Edited by Hopkins PM, Bodenham AR and Reeves ST by Informa Healthcare USA, 6: p 71-85, 2008.
4- BLANCOA R., FAJARDOB M. and PARRAS M.T. Ultrasound description of PECS II (modified PECS I): A novel approach to breast surgery; by Elsevier Espana. Rev. Esp. Anestesiol. Reanim., 59: 470-75, 2012.

5- KHALIL A.E., ABDALLAH N.M., GHADA M., BASHANDY G.M. and KADDAH T.A.: Ultrasound Guided Serratus Anterior Plane Block Versus Thoracic Epidural Analgesia for Thoracotomy Pain; Journal of Cardiothoracic and Vascular Anesthesia: Feb., 31 (1): 152-158,2017.

6- BASHANDY G.M.N. and ABBAS D.: Pectoral Nerves I and II Blocks in Multimodal Analgesia for Breast Cancer Surgery A Randomized Clinical Trial; Reg. Anesth. Pain Med., 40: 68-74, 2015.

7- ELDEEN H.M.S.: Ultrasound guided pectoral nerve blockade versus thoracic spinal blockade for conservative breast surgery in cancer breast: A randomized controlled trial; Egyptian Journal of Anaesthesia, 32: 2935, 2016.

8- RAZEK A.A., ABOUALLO M.M., ABDEL HAMID Sh.A. and OSMAN M.D.: Ultrasound guided pectoral nerve blocks versus serratus intercostal plane block in breast surgeries. "Hot \& Cold Pack- Caldera International", Vol. 5, pp. 162-169, 2018.

9- MORIOKA H., KAMIYA Y., YOSHIDA T. and BABA H.: Pectoral nerve block combined with general anesthesia for breast cancer Surgery: A retrospective comparison; JA Clinical Reports, 1: 15, 2015.

10- TORRE P.A., JONES Jr. J.W., ÁLVAREZ S.L., GARCIA P.D., MIGUEL F.J., RUBIO E.M., BOERIS F.C., SACRAMENTO M.K., DUANY O., PÉREZ M.F. and GORDON B.D.: Axillary local anesthetic spread after the thoracic interfacial ultrasound block-a cadaveric and radiological evaluation. Revista brasileira de anestesiologia. Dec., 67 (6): 555-64, 2017.

11- SONI S., SONI A., BAPUGOL M., MOHAMMED S., KARNAWAT R. and TULSIANI K.L.: Comparision of thoracic epidural block vs paravertebral block in patients undergoing breast surgery. Indian Journal of Clinical Anaesthesia. Jan., 2 (1): 48-56, 2015.

12- YUKI I., UESHIMA H., OTAKE H. and KITAMURA A.: PECS Block Provides Effective Postoperative Pain Management for Breast Cancer Surgery-A Retrospective Study; International Journal of Clinical Medicine, 8: 198203, 2017.

13- LI, NAI-LIANG, BEN-LONG YU, and CHEN-FANG HUNG: "Paravertebral block plus thoracic wall block versus paravertebral block alone for analgesia of modified radical mastectomy: A retrospective cohort study". PloS One 11, No. 11, e0166227, 2016. 


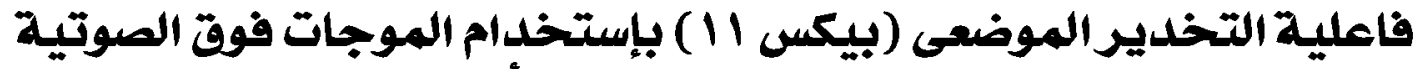

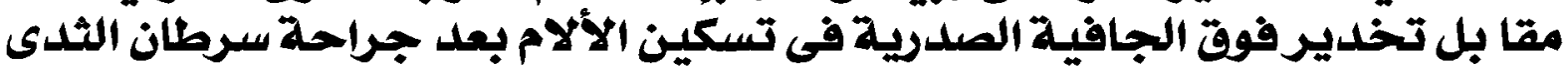

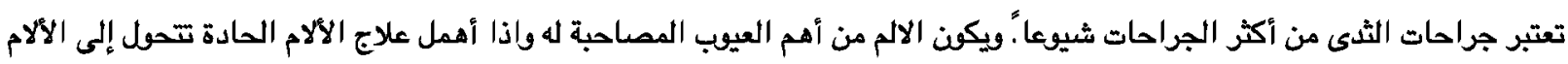

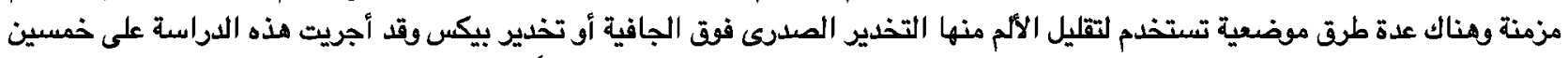

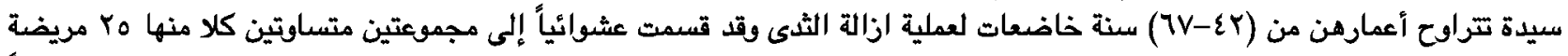

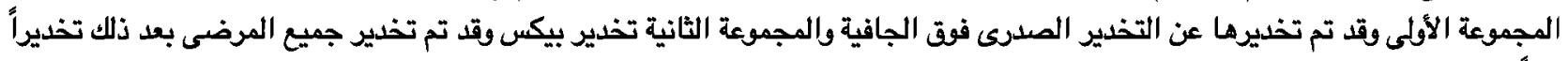

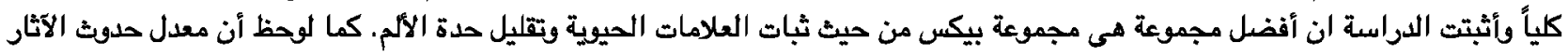

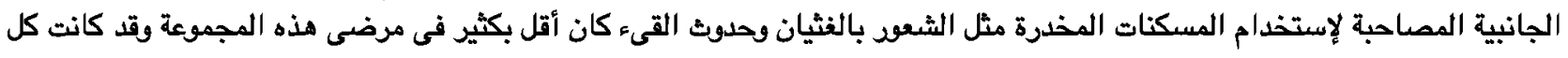
هذه التتائج ذات مدلول إحصائى. 